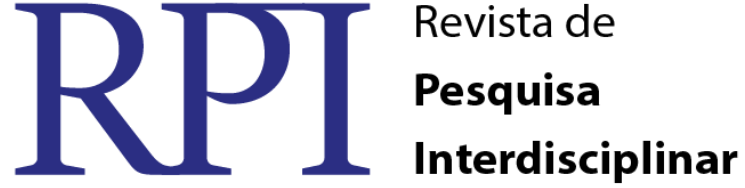

\section{A UTILIZAÇ̃̃o DE DOCUMENTÁRIOS DIDÁTICOS NO ENSINO DE BIOLOGIA NA EJA DA CIDADE DE SÃO JOSÉ DE PIRANHAS - PB}

\author{
Moniky Mendes Maciel ${ }^{1}$ \\ Pricila Bento Gonçalves ${ }^{2}$ \\ José Deomar de Souza Barros ${ }^{3}$
}

\begin{abstract}
RESUMO
A Educação de Jovens e Adultos oportuniza as pessoas que não tiveram acesso ou continuidade de estudos no Ensino Fundamentai e Médio em idade convencional, assim como, objetiva prepará-los para o mercado de trabalho e o pleno exercício da cidadania. Na EJA os educadores devem considerar o processo histórico dos seus alunos, tendo a consciência da abordagem do ensino, que deve ser feito de maneira diferenciada e associada à realidade dos discentes. Com isso, a inserção das novas Tecnologias da Informação e da Comunicação (TICs) na EJA torna-se importante para a apropriação das práticas sociais de leitura e escrita, na vida social e profissional do sujeito de maneira significativa. $\mathrm{O}$ uso das TICs pode ser uma forma de inovar na educação, com um trabalho coletivo de reflexão sobre a realidade e de mudanças conceituais. Assim, a presente pesquisa teve por objetivo avaliar a eficácia da utilização de documentários didáticos no ensino de Biologia na EJA da cidade de São José de Piranhas - PB. A presente pesquisa foi realizada na Escola Estadual de Ensino Médio Prefeito Joaquim Lacerda Leite, na cidade de São José de Piranhas - PB, no período de 23 a 30 de agosto de 2016, com alunos do ciclo V (Ensino Médio) da Educação de Jovens e Adultos - EJA, onde houve uma intervenção pedagógica por meio da exibição de um documentário sobre sistema digestório, e posteriormente a aplicação de um questionário com o objetivo de verificar a eficácia do documentário como modalidade didática. Os resultados obtidos indicam que a utilização de documentários didáticos são eficientes na construção do conhecimento em biologia, uma vez que os alunos conseguiram compreender todo o processo de digestão que acontece no nosso corpo, associando esse conhecimento com o seu cotidiano. Proporcionado assim ao alunado uma aprendizagem mais significativa.
\end{abstract}

Palavras-Chave: EJA. Documentário. Sistema Digestório.

\section{THE USE A didactic DOCUMENTARY IN BIOLOGY TEACHING IN EJA in CITY OF SÂO JOSÉ DE PIRANHAS - PB}

\section{ABSTRACT}

The Youth and Adult Education provides opportunities to people who did not have access or continuity of studies in Fundamentai and high school age in conventional as well as objective to prepare them for the labor market and the full exercise of citizenship. In EJA educators must consider the historical process of their students, and the awareness of the teaching approach, which should be done differently and linked to the reality of students way. Thus, the inclusion of the new Information

\footnotetext{
${ }^{1}$ Graduanda em Ciências Biológicas - Licenciatura pela Universidade Federal de Campina Grande - UFCG. E-mail: moniky.mendesmaciel@gmail.com

${ }^{2}$ Graduanda em Ciências Biológicas - Licenciatura pela Universidade Federal de Campina Grande - UFCG. E-mail: bentopricila@gmail.com

${ }_{3}^{3}$ Licenciado em Ciências com Habilitação em Biologia e em Química pela Universidade Federal de Campina Grande UFCG. Especialista em Agroecologia pela Universidade Federal da Paraíba - UFPB. Especialista em Ensino de Química pela Universidade Regional do Cariri - URCA. Mestre e Doutor em Recursos Naturais pela Universidade Federal de Campina Grande - UFCG. Professor Adjunto da Universidade Federal de Campina Grande - UFCG. E-mail: deomarbarros@gmail.com
} 
Technology and Communication (ICT) in adult education becomes important for the appropriation of the social practices of reading and writing, in social and professional life of the subject significantly. The use of ICTs can be a way to innovate in education, with a collective work of reflection on reality and conceptual changes. Thus, the present study was to evaluate the effectiveness of the use of educational documentaries in teaching biology at EJA in São José de Piranhas - PB. This research was conducted at the Escola Estadual de Ensino Médio Prefeito Joaquim Lacerda Leite, in the city of São José de Piranhas - PB, in from 23 to 30 August 2016, with students of the V cycle (high school) of the Youth Education and Adults - EJA, where there was an educational intervention through the screening of a documentary on the digestive system, and then the application of a questionnaire in order to verify the effectiveness of the documentary as a teaching mode. The results indicate that the use of educational documentaries are efficient in the construction of knowledge in biology, since the students were able to understand the whole process of digestion happens in our body, combining this knowledge with their daily lives. Thus provided to the student body a more meaningful learning.

Keywords: Adult Education. Documentary. Digestive System.

\section{INTRODUÇÃO}

Muitas pessoas não tiveram a oportunidade de estudar ou de concluir os seus estudos na idade convencional, em decorrência desse fato o número de analfabetos é significativo no Brasil, segundo IBGE (2010), no último Censo realizado, 9\% da população brasileira não sabem ler nem escrever.

O Ministério da Educação - MEC criou em 2008, a Educação de Jovens e Adultos (EJA), que é uma modalidade da Educação Básica nas etapas do Ensino Fundamental e Médio pautada na Lei de Diretrizes e Bases da Educação Nacional, $\mathrm{n}^{\circ}$ 9.394/96, que consta no inciso $\mathrm{V}$, capítulo II, estando está destinada a pessoas que não tiveram acesso ou continuidade de estudos nos ensinos fundamental e médio em idade própria (RAMAL, 1997; BRASIL, 1996).

A utilização de recursos audiovisuais pode ser uma estratégia didática metodológica capaz de atrair o aluno para que ele possa se tornar sujeito ativo na construção do seu próprio conhecimento, por meio da contextualização dos conteúdos apresentados em sala de aula.

Os conteúdos de biologia abordados em sala de aula devem ser trabalhados com estratégias metodológicas que os tornem interessantes e instigantes para os educandos da EJA, tendo em vista que estes conteúdos precisam estar relacionados ao cotidiano do aluno. A inserção das novas Tecnologias da Informação e da Comunicação (TICs) na EJA torna-se importante para a apropriação das práticas sociais de leitura e escrita, na vida social e profissional do sujeito de maneira significativa. O uso das TICs pode ser uma forma de inovar 
na educação, com um trabalho coletivo de reflexão sobre a realidade e de mudanças conceituais.

Os discentes da EJA possuem um vasto conhecimento de senso comum, neste aspecto a educação voltada para este público precisa ser diferenciada da educação voltada para crianças e adolescentes no ensino convencional. Haja vista que esta modalidade de ensino agrupa uma grande diversidade de pessoas, justificando a necessidade de possuir materiais e metodologias especificas para o processo de ensino e aprendizagem, sendo importante que a educação, em todas as modalidades, favoreça a reflexão e o diálogo. E a utilização de recursos audiovisuais, como os documentários, pode ser vista como um alternativa viável para construção desses saberes.

Assim, a presente pesquisa teve como objetivo avaliar a eficácia da utilização de documentários didáticos no ensino de Biologia na EJA da cidade de São José de Piranhas PB.

\section{Metodologia}

A pesquisa foi desenvolvida no dia 23 a 30 de agosto de 2016, com a transmissão de um documentário, intitulado Sistema Digestório e logo em seguida foi aplicado um questionário.

\section{Caracterização da área de estudo}

A pesquisa foi realizada na Escola Estadual de Ensino Médio Prefeito Joaquim Lacerda Leite, localizada na Rua Raimundo Alves, Bairro Santo Antônio, na cidade de São José de Piranhas - PB, com alunos do ciclo V (Ensino Médio) da Escola de Jovens e Adultos - EJA.

\section{Classificação da pesquisa}

RPIRevista de Pesquisa Interdisciplinar, Cajazeiras, v. 1, Ed. Especial, 99 - 105, set/dez. de 2016. 
Para a classificação da pesquisa adotou-se a metodologia de Costa e Costa (2013), do ponto de vista da sua natureza, a pesquisa é classificada como aplicada. Quanto a forma de abordagem do problema é uma pesquisa qualitativa. Em relação aos objetivos trata-se de uma pesquisa exploratória e quanto aos procedimentos técnicos a pesquisa é classificada como pesquisa-ação.

\section{Sujeitos da pesquisa}

Os sujeitos da pesquisa foram 06 (seis) alunos matriculados no ciclo V (Ensino Médio) da Escola de Jovens e Adultos - EJA.

\section{Intervenção didática}

No processo de intervenção pedagógica foi realizada inicialmente uma intervenção didática por meio de uma exposição oral e exibição de um documentário sobre sistema digestório, durante a intervenção foram realizados debates sobre a temática e por último foi aplicado um questionário de sondagem com perguntas subjetivas, relacionadas ao conteúdo do documentário para avaliar a eficácia do documentário na construção do conhecimento biológico acerca da temática sistema digestório.

\section{Análise dos resultados}

Os resultados foram analisados por meio da categorização de respostas dos discentes no questionário e nas observações realizadas durante os debates.

\section{Resultados e Discussões}

Após a apresentação do documentário: Sistema Digestório, e a aplicação do questionário, foi possível verificar, com base nas respostas dos alunos, que todos gostaram do documentário, relacionando-o ao conteúdo de biologia: o sistema digestório. Verificando assim que os alunos conseguiram identificar qual o tema estava relacionado com o documentário. Logo após, indagamos sobre onde se iniciava o processo de digestão e todos responderam que iniciava na boca.

De acordo com Cavalcante (2011), além da importância do aprendizado dos conteúdos de biologia, os alunos devem desenvolver uma visão de mundo que pode ser proporcionada RPIRevista de Pesquisa Interdisciplinar, Cajazeiras, v. 1, Ed. Especial, 99 - 105, set/dez. de 2016. 
pelo professor na sala de aula, e uma técnica eficaz de interligar essas duas linhas de pensamento, é o uso de filmes/documentários como metodologia didática. Fazendo com que o ensino de biologia não seja apenas a mera abordagem de conhecimentos biológicos, mas, que possa proporcionar a reflexão e a formação do pensamento crítico.

Quando questionados sobre os alimentos que precisamos consumir para que tenhamos uma alimentação saudável, e qual a importância desses alimentos, todos os alunos responderam citando alguns exemplos como as frutas e verduras, relacionando esses alimentos por fornecer os nutrientes necessários para o funcionamento do nosso corpo.

Frutas porque contém nutrientes e vitaminas, onde fornecem energia e ajudam na manutenção do nosso corpo (Aluno D).

Não podemos viver sem se alimentar por que os alimentos fornecem energia (Aluno B).

Segundo as Orientações Curriculares para o Ensino Médio (BRASIL, 2006), o aluno precisa compreender o alimento como fonte de energia e matéria para crescimento e manutenção do corpo humano e distinguir os diferentes tipos e a importância dos nutrientes necessários.

Quando perguntados se era possível engolirmos um alimento de cabeça para baixo, todos os discentes responderam que sim, afirmando que isso era possível graças as contrações involuntárias realizadas pela nosso corpo, como pode ser observado no seguinte relato: "Graças aos movimentos peristálticos." (Aluno C).

Quando indagados sobre o porquê do nosso trato digestivo ser dobrado, os alunos afirmaram que era necessário para que se encaixasse no nosso corpo. E fizeram um relato sobre o documentário, afirmado que se não fosse assim, teríamos que ter 9 (nove) metros de altura.

Durante o documentário é explicado o momento da deglutição, e um aluno relatou que já tinha tentado engolir e respirar ao mesmo tempo, mas, não conseguiu, acrescentando que não sabia o porquê. E na análise das respostas dos questionários, todos os alunos descreveram o processo de deglutição, em que um dos alunos relata: "Não conseguimos respirar e engolir por causa da epiglote, quando engolimos um alimento ela se fecha liberando a passagem da comida, e quando respiramos ela se abre para que o ar vá para os pulmões.”

Lourenço e Barros (2016), realizaram um trabalho semelhante, na qual os mesmo pediram para que os alunos bebessem um copo de água e sentissem os movimentos RPIRevista de Pesquisa Interdisciplinar, Cajazeiras, v. 1, Ed. Especial, 99 - 105, set/dez. de 2016. 
peristálticos durante e depois da deglutição, para analisar se seria possível ou não respirar enquanto se engolia a água. $\mathrm{Na}$ oportunidade, os discentes concluíram que não era possível realizar as duas coisas ao mesmo tempo. Estes resultados corroboram com os dados da presente pesquisa.

Nesse momento foi levantada uma questão para debate em sala de aula, discutimos sobre o fato dos bebês mamarem durante muito tempo, em que indagaram como isso seria possível. Alguns chegaram a afirmar que os bebês conseguiam passar todo esse período de amamentação sem respirar, mas, quando perguntados se eles conseguiriam passar alguns minutos sem respirar, todos afirmaram que não. Em seguida, foi explicado para os alunos que os bebês não conseguiriam ficar todo esse tempo sem respirar, mas, que eles conseguiam respirar e comer simultaneamente, graças a uma adaptação da sua epiglote, que é mais alta do que as dos adultos.

Quando questionados sobre a função da bile no nosso organismo, todos os alunos responderam que sua função era quebrar a gordura dos alimentos ingeridos na alimentação, e dando continuidade a todo o processo de digestão, foi perguntado aos alunos o que acontecia com os restos alimentares que não eram aproveitados pelo nosso corpo, e todos responderam que seriam excretados pelas fezes ou urina, saindo automaticamente do nosso organismo.

Segundo Lourenço e Barros (2016), as aulas podem ser trabalhadas por meios de recursos audiovisuais, como documentário, que possibilita ao educador tornar a aula lúdica e inovadora, desconstruindo o ensino tradicional e facilitando a aprendizagem dos alunos.

\section{Conclusão}

Na utilização do documentário "Sistema Digestório", foi possível observar que os alunos conseguiram compreender corretamente como ocorre o processo de digestão do nosso corpo. Associando todos os assuntos abordados no vídeo com a sua realidade. A utilização de documentários no ensino da EJA, pode ser considerada uma boa alternativa para que os alunos compreendem aspectos fisiológicos do nosso corpo, uma vez que a maioria das escolas públicas não possuem modelos anatômicos para aulas práticas, e o documentário pode suprir essa carência, apresentando de forma lúdica e compreensível os conteúdos vistos em sala.

Foi possível verificar a eficácia da exibição de documentários no processo ensino/aprendizagem na EJA, possibilitando aos alunos uma melhor compreensão do 
conteúdo. O aluno da EJA traz conhecimentos baseados no seu cotidiano, que se forem respeitados, podem ser aproveitados para a construção de novos conhecimentos, os debates, discussões e reflexões podem auxiliar na construção do conhecimento científico.

\section{REFERÊNCIAS}

BRASIL. IBGE. Censo Demográfico, 2010. Disponível em: <http://7a12.ibge.gov.br/vamosconhecer-o-brasil/nosso-povo/educacao.html>. Acesso em: 04 de set. 2016.

BRASIL. Ministério da Educação. Secretaria de Educação Média e Tecnológica (Semtec). PCN Ensino Médio: orientações educacionais complementares aos Parâmetros Curriculares Nacionais - Ciências da Natureza, Matemática e suas Tecnologias. Brasília: MEC/Semtec, v. 2, p. 1- 42, 2006.

BRASIL. Lei $\mathrm{N}^{\circ}$ 9.394, de 20 de dezembro de 1996. Estabelece as diretrizes e bases da educação nacional. Diário Oficial da República Federativa do Brasil, Brasília, Seção I, p. 27.833, 23 dez. 1996.

CAVALCANTI, E. C. B. Cinema na cela de aula: o uso de filmes no Ensino de Biologia para o EJA prisional. 2011. 153f. Dissertação (Mestrado Profissional em Ensino de Ciências)Universidade de Brasília - DF, 2011.

COSTA, M. A. D. da; COSTA, M. de F. B. da. Projeto de pesquisa: entenda e faça. Petrópolis: Vozes, 2013.

LOURENÇO, F. H. S. de M; BARROS, J. D. de S. A máquina alimentar: o uso de documentários no ensino de anatomia e fisiologia humana na educação de jovens e adultos do sistema prisional de Cajazeiras-PB. In: Congresso Nacional de Ensino e Pesquisa em Ciências, 1, 2016, Campina Grande. Anais... Campina Grande: Realize, 2016.

RAMAL, A. C. A nova LDB: destaques, avanços e problemas. Revista de Educação CEAP, v. 5, n. 17, p. 05-21, 1997. 